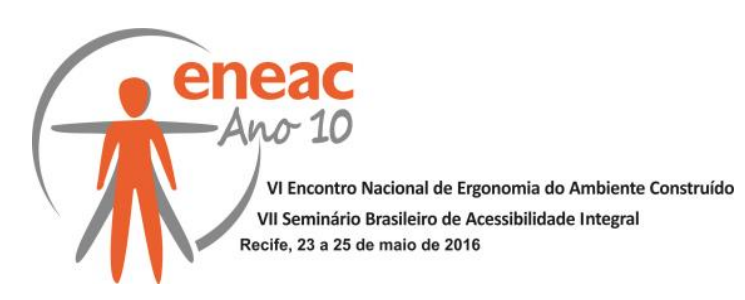

\title{
AVALIACCÃO PÓS OCUPACIONAL DO COMPLEXO ESPORTIVO E DO SALẤO DE EVENTOS MUNICIPAL EM IGARAÇU DO TIETÊ/SP
}

\author{
DINIZ, Rogério (1); \\ RIBEIRO, Daniel Gutierrez (2); \\ ZEBINI, Alisson Otávio (3); \\ STRABELI, Giovana Innocenti (4) \\ (1) Universidade Sagrado Coração, Graduado \\ e-mail:diniz_rogerio@hotmail.com \\ (2) Universidade Sagrado Coração, Graduado \\ e-mail: danielgutierrezribeiro@hotmail.com \\ (3) Universidade Sagrado Coração, Graduado \\ e-mail: alisson_zebini@hotmail.com \\ (4) Universidade Sagrado Coração, Mestre \\ e-mail: giovana.strabeli@usc.br
}

\begin{abstract}
RESUMO
O presente trabalho é o produto final da disciplina de Avaliação Pós-Ocupacional do curso de Arquitetura e Urbanismo da Universidade do Sagrado Coração, O objetivo principal é a aplicação de métodos e ferramentas mais relevantes na A.P.O., fundamentada nos conceitos da psicologia ambiental, no Complexo Esportivo e Salão de Eventos Municipal em Igaraçu do Tietê/SP. Para o desenvolvimento desta pesquisa foram realizadas visitas a campo, aplicando-se os instrumentos para coleta de dados, cujo os resultados e as recomendações de melhoria serão apresentados no decorrer do trabalho.
\end{abstract}

Palavras chave: avaliação pós-ocupacional; mapa comportamental; walkthrough.

\section{ABSTRACT (11 PTS, NEGRITO)}

This work is the final product of discipline Post-Occupational Evaluation of the Architecture and Urbanism at the Universidade do Sagrado Coração. The main objective is the application of the most important methods and tools of POE, based on the concepts of environmental psychology in the Municipal Sports Complex and Convention Center in Igaraçu do Tiete / SP. For the development of this research were conducted field visits, applying the tools for data collection, whose findings and recommendations for improvement will be presented during the work.

Keywords: post-occupational evaluation; behavioral map; walktrough.

\section{INTRODUÇÃO}

A análise do Complexo Esportivo e do Salão de Eventos Municipal identificou as qualidades e os problemas do espaço, apontando as diretrizes para sua melhoria, de forma a aumentar o bem estar dos usuários que frequentam o local, em função do que foi observado. A metodologia de investigação multidisciplinar utilizada na APO tem papel importante na 


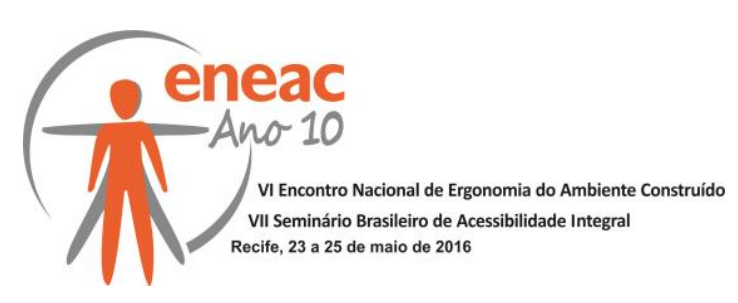

pesquisa do espaço construído sob o ponto de vista do usuário, pois fornece subsídios para o planejamento de futuras intervenções e para projetos futuros semelhantes (RHEINGANTZ et al., 2009).

O presente relatório poderá ser apresentado à secretaria de esportes do município com a intenção de ser útil para futuras adequações, além de informá-los mais especificamente sobre aspectos que, de maneira geral, passam despercebidos em relação à ambiência do espaço em estudo. Para a comunidade acadêmica a pesquisa auxiliará para reforçar a importância da percepção do espaço para os usuários, além da avaliação de seus aspectos físicos, que é repleto de significados subjetivos; resultados de seu uso.

O primeiro dia da visita foi determinante para o planejamento estratégico de aplicação das ferramentas de análise. Assim, as próximas visitas ao local, já foram aplicadas a avaliação Walkthrough, Mapa Comportamental, Mapeamento Visual, Questionário e Entrevista. Através da análise dos resultados obtidos pela Matriz de Descobertas, foram elaboradas as recomendações a curto, médio e longo prazo.

Ao final do presente relatório, será feito um cruzamento de dados apresentando os pontos relevantes identificados pelos instrumentos, para garantir que as recomendações estejam atingindo as principais demandas do local. Nas considerações finais são discutidos os métodos empregados e a sua validade no estudo de caso proposto.

\subsection{Justificativa}

A cidade de Igaraçu do Tietê/SP, localizada no Centro Oeste do Estado de São Paulo, oferece poucos espaços voltados para o lazer e a recreação da população. Um desses espaços é o Complexo Esportivo e o Salão de Eventos Municipal José Antonio Varasquim, que se encontra, em estado de abandono. Os ambientes que compõem o espaço são: o salão de eventos, o ginásio de esportes coberto, as piscinas adulto e infantil, as canchas de bocha e o campo society de gramado sintético. A área das piscinas e o salão de eventos não estão sendo utilizados pela população, somente o ginásio, o campo e as canchas de bocha, esta última frequentemente aos finais de semana.

A avaliação pós-ocupação foi definida para o Complexo Esportivo e o Salão de Eventos Municipal na Estância Turística de Igaraçu do Tietê, principalmente pela sua identidade e importância social para a comunidade. Além disso, existe uma preocupação com os ambientes oferecidos, que possuem diversos problemas decorrentes da falta de manutenção, do vandalismo por parte da população, das características dos materiais construtivos utilizados e o abandono do poder público.

\subsection{Objetivos}

Os principais objetivos são:

a) realizar um levantamento dos equipamentos oferecidos pelo espaço em estudo através de visitas técnicas;

b) aplicar as ferramentas e métodos da A.P.O. visando absorver e compreender como a comunidade e os usuários percebem, observam e interagem com 0 complexo esportivo e recreativo;

c) elaborar as recomendações a curto, médio e longo prazo, que poderão servir como base para futuras intervenções e melhorias do espaço. 


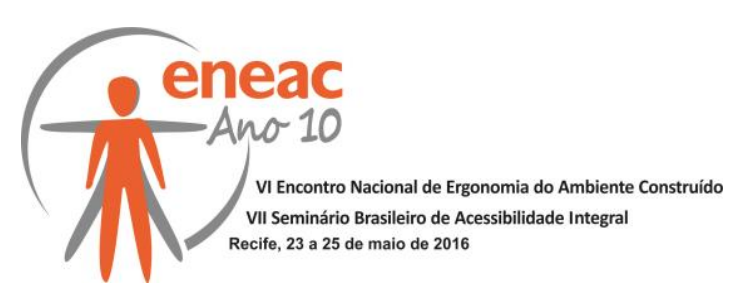

\subsection{Metodologia}

A abordagem utilizada teve seu foco nas pessoas (usuários), na descoberta de seus anseios, expectativas, comportamentos, aspectos positivos e negativos relacionados ao local de estudo. Faz parte de uma abordagem relacionada ao projeto participativo (WULZ, 1986), onde a percepção da comunidade é relevante para a tomada de decisões relacionadas ao projeto.

As ferramentas utilizadas são baseadas em dinâmicas individuais (mapeamento visual); métodos indiretos (questionários e entrevistas) e a observação por meio da análise walkthrough e mapa comportamental.

\section{CONTEXTUALIZAÇÃO SOBRE AVALIAÇÃo PÓS-OCUPAÇÃO}

A APO é uma aferição da qualidade do ambiente construído, sempre relacionando a seus fins para com os seus usuários. Segundo Rheingantz et al. (2009, p. 16), a APO é um processo interativo, sistematizado e rigoroso de avaliação do desempenho do ambiente construído, passado algum tempo de sua construção e ocupação.

Sendo assim, se ocupa não da qualidade como potência ou de modo universal, mas se refere à qualidade associada às necessidades de seu propósito, levantada a partir da experiência de seus usuários e de seus níveis de satisfação. A influência e as consequências das decisões projetuais são, assim avaliadas, especialmente as relacionadas à percepção e 0 uso por parte dos diferentes agentes envolvidos. (RHEINGANTZ et al., 2009).

Entende-se desempenho ou eficiência do ambiente construído como um fator relativo, dependente do propósito da edificação e seu programa arquitetônico e, consequentemente, da relação ambiente $x$ usuário neste ambiente especificamente. (RHEINGANTZ et al., 2009).

O objeto de estudo deste trabalho é o Complexo Esportivo e Salão de Eventos Municipal em Igaraçu do Tietê/SP, situado à Avenida José Michel Mucare, no bairro Jardim Novo Estilo. $O$ espaço foi inaugurado em outubro de 1978 (Figuras 1 e 2).

Figura 1: Localização do Complexo Esportivo e do Salão de Eventos Municipal.

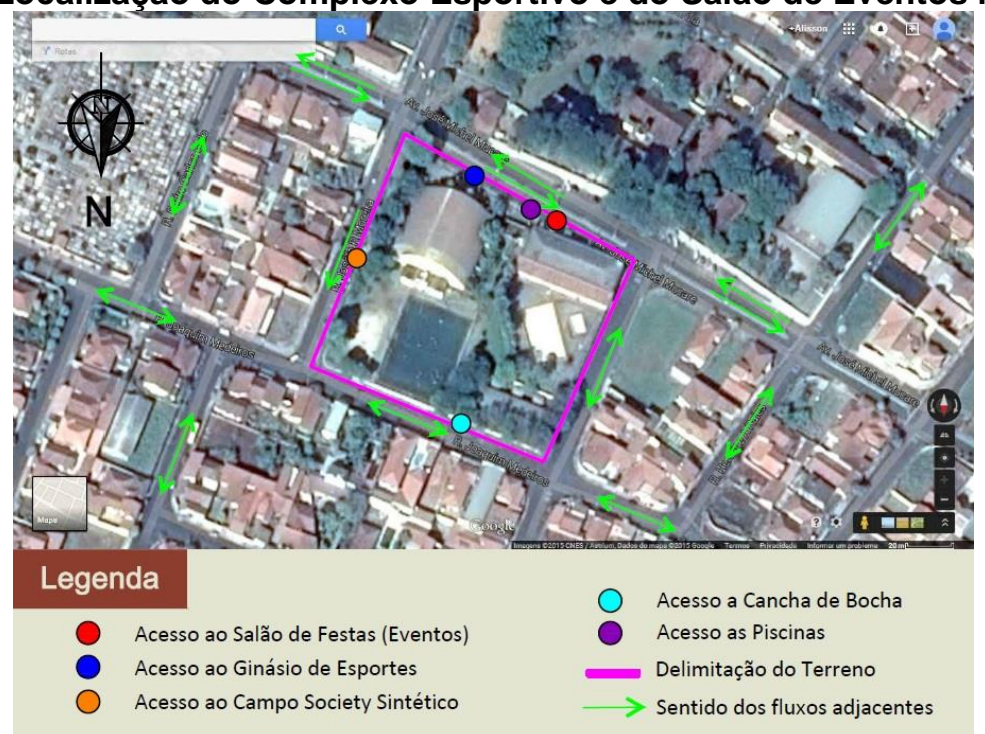

Fonte: Google Maps (2015).

Nota: Adaptado pelos autores. 


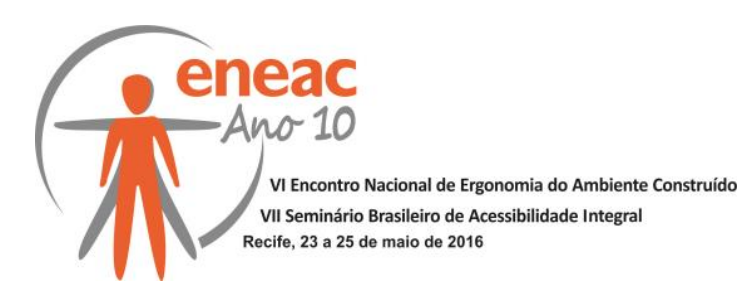

Figura 2: Implantação geral atual do espaço em estudo.

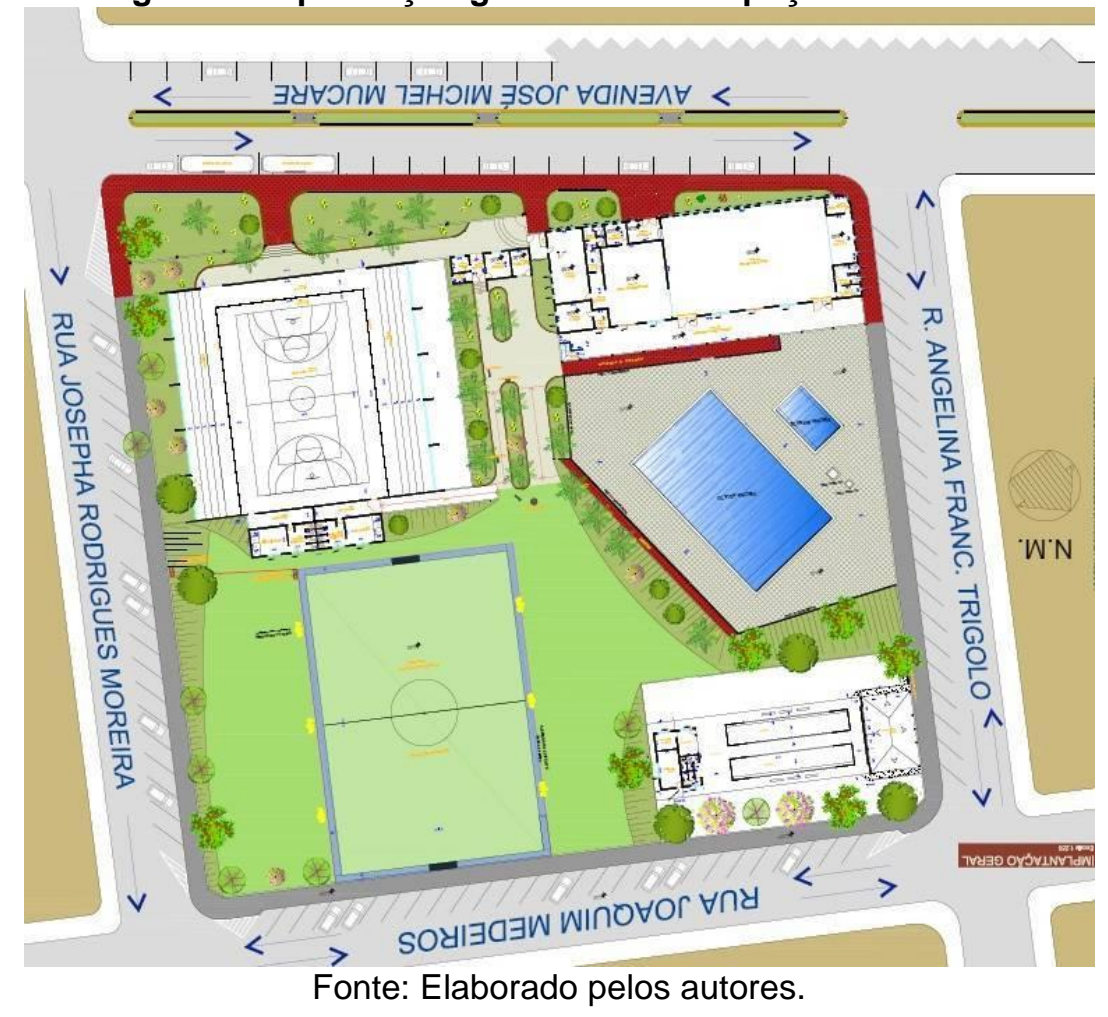

O espaço é utilizado pela comunidade como local para a realização de competições esportivas municipais e regionais incluindo: futsal, basquete, voleibol, bocha, futebol society, etc.; também para eventos comemorativos e recreativos como: bailes, festas municipais, palestras, reuniões, etc.

\section{PESQUISA DE CAMPO}

Os métodos e ferramentas aplicados na avaliação pós-ocupação estão descritos a seguir.

\subsection{Análise Walkthrough}

A ferramenta walkthrough foi aplicada ao Complexo Esportivo e ao Salão de Eventos Municipal no dia 4 de março de 2015, além da análise dos pesquisadores, foram realizadas documentação fotográfica com a autorização da Guarda Municipal.

Para sua aplicação, foi elaborado um modelo de checklist (Figura 3), que serviu para a avaliação geral da edificação, por parte dos pesquisadores e, contando ainda, com a participação de 30 usuários. Apresentava a seguinte pergunta: "Como você avalia o Complexo Esportivo e Recreativo em termos gerais?" abordando, para tal, quatro grupos focais: aspectos estético-compositivos; aspectos técnicos construtivos; aspectos contextuais ambientais e aspectos programáticos funcionais. 


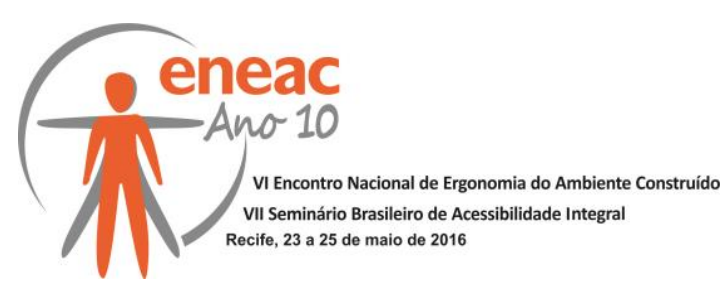

Figura 3: Checklist

\section{MODELO DE QUESTIONÁRIO APLICADO PARA AVALIAÇÃO DO DESEMPENHO DO AMBIENTE CONSTRUÍDO}

\begin{tabular}{|c|c|c|c|c|c|c|c|}
\hline Nome: & & & & & & & \\
\hline \multicolumn{8}{|l|}{ Idade: } \\
\hline Sexo: & \multicolumn{7}{|l|}{ (1) M (I) F } \\
\hline \multicolumn{8}{|l|}{$\begin{array}{l}\text { Onde } \\
\text { Mora }\end{array}$} \\
\hline & & \multicolumn{6}{|c|}{ Notas } \\
\hline № & Aspectos & MR & $\mathbf{R}$ & $\mathbf{R R}$ & RB & B & MB \\
\hline 01 & Manutenção adequada & 01 & 02 & 03 & 04 & 05 & 06 \\
\hline 02 & Conservação dos objetos & 01 & 02 & 03 & 04 & 05 & 06 \\
\hline 03 & Segurança do Bairro & 01 & 02 & 03 & 04 & 05 & 06 \\
\hline 04 & Facilidade de Acesso & 01 & 02 & 03 & 04 & 05 & 06 \\
\hline 05 & Acessibilidade & 01 & 02 & 03 & 04 & 05 & 06 \\
\hline 06 & Conforto & 01 & 02 & 03 & 04 & 05 & 06 \\
\hline 07 & Aparência Geral & 01 & 02 & 03 & 04 & 05 & 06 \\
\hline 08 & Acabamento dos materiais & 01 & 02 & 03 & 04 & 05 & 06 \\
\hline 09 & Segurança do Complexo & 01 & 02 & 03 & 04 & 05 & 06 \\
\hline 10 & Limpeza & 01 & 02 & 03 & 04 & 05 & 06 \\
\hline 11 & Ruídos externos & 01 & 02 & 03 & 04 & 05 & 06 \\
\hline 12 & Circulação & 01 & 02 & 03 & 04 & 05 & 06 \\
\hline 13 & Iluminação Natural & 01 & 02 & 03 & 04 & 05 & 06 \\
\hline 14 & Localização & 01 & 02 & 03 & 04 & 05 & 06 \\
\hline 15 & Ventilação Natural & 01 & 02 & 03 & 04 & 05 & 06 \\
\hline 16 & Odores & 01 & 02 & 03 & 04 & 05 & 06 \\
\hline 17 & Dimensões ambientes & 01 & 02 & 03 & 04 & 05 & 06 \\
\hline 18 & Vegetação & 01 & 02 & 03 & 04 & 05 & 06 \\
\hline 19 & Estacionamento & 01 & 02 & 03 & 04 & 05 & 06 \\
\hline 20 & Temperatura interna & 01 & 02 & 03 & 04 & 05 & 06 \\
\hline 21 & Sinalização & 01 & 02 & 03 & 04 & 05 & 06 \\
\hline 22 & Entorno & 01 & 02 & 03 & 04 & 05 & 06 \\
\hline
\end{tabular}

Fonte: Elaborado pelos autores.

Em relação as análises do checklist, do item 01 ao 13 os resultados apresentados foram regulares, com destaque para os dois primeiros itens que expressa a atual realidade do equipamento público: a falta de manutenção adequada e de conservação dos objetos (Figuras 4 e 5 ) 


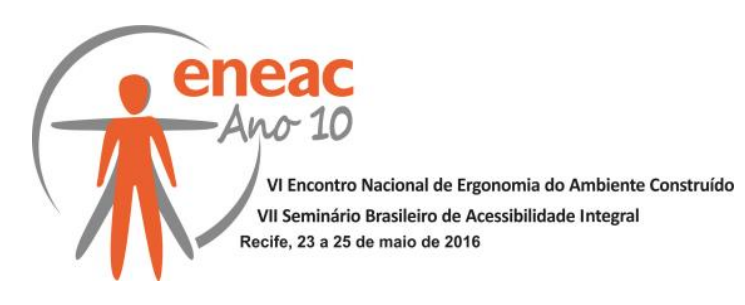

Figura 4: Piscina

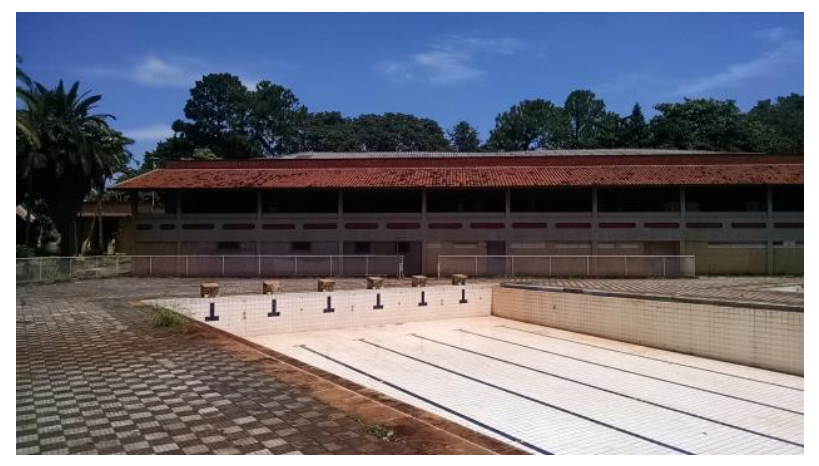

Fonte: Elaborado pelos autores.
Figura 5: Campo Society

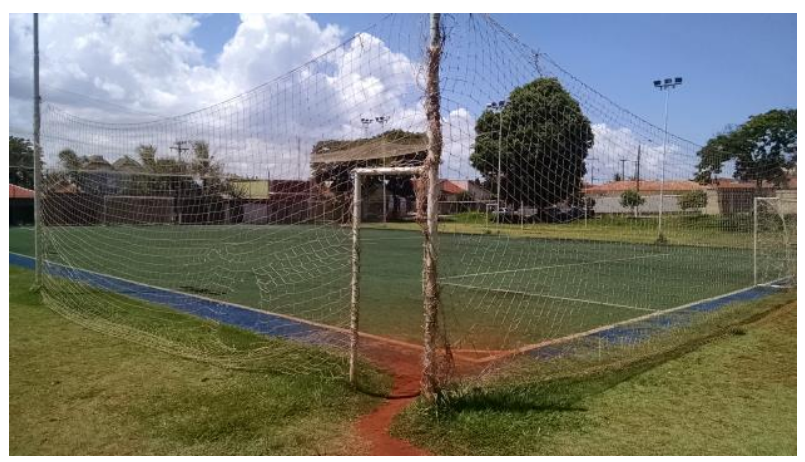

Fonte: Elaborado pelos autores.

Posteriormente, do item 14 ao 22 houve uma melhora expressiva nos resultados, e o item 14 foi o único que teve votos de relativamente ou superiores, ressaltando a boa localização do complexo na cidade.

Ao examinar todos os aspectos do checklist, concluiu-se que a maioria dos itens foi identificada como relativamente boas, entretanto, na comparação da somatória dos aspectos positivos versus dos aspectos negativos, estes últimos se sobressaíram.

\subsection{Mapeamento Visual}

O mapeamento visual é um instrumento que permite identificar a percepção dos usuários em relação a um determinado ambiente, focalizando a localização, a apropriação e a demarcação de territórios, as inadequações a situações existentes, o mobiliário excedente ou inadequado, as barreiras, entre outras características (RHEINGANTZ et al., 2009).

Este instrumento foi aplicado segundo as seis áreas do complexo: administração, salão de eventos, ginásio de esportes, cancha de bocha, campo society e por fim a área das piscinas. Foram entregues formulários para doze usuários e três funcionários, com sugestões de sensações para que fossem assinalados os ambientes onde eram percebidas. A partir de então, foi realizada a classificação do resultado em categorias com a elaboração de um quadro com as sensações e as frequências com que aparecem em diversos ambientes do complexo. Um gráfico para melhor compreensão do resultado também foi elaborado (Figura $6)$. 


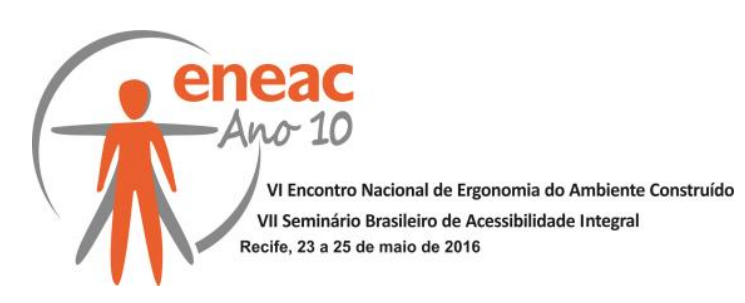

Figura 6: Gráfico do resultado das sensações avaliadas.

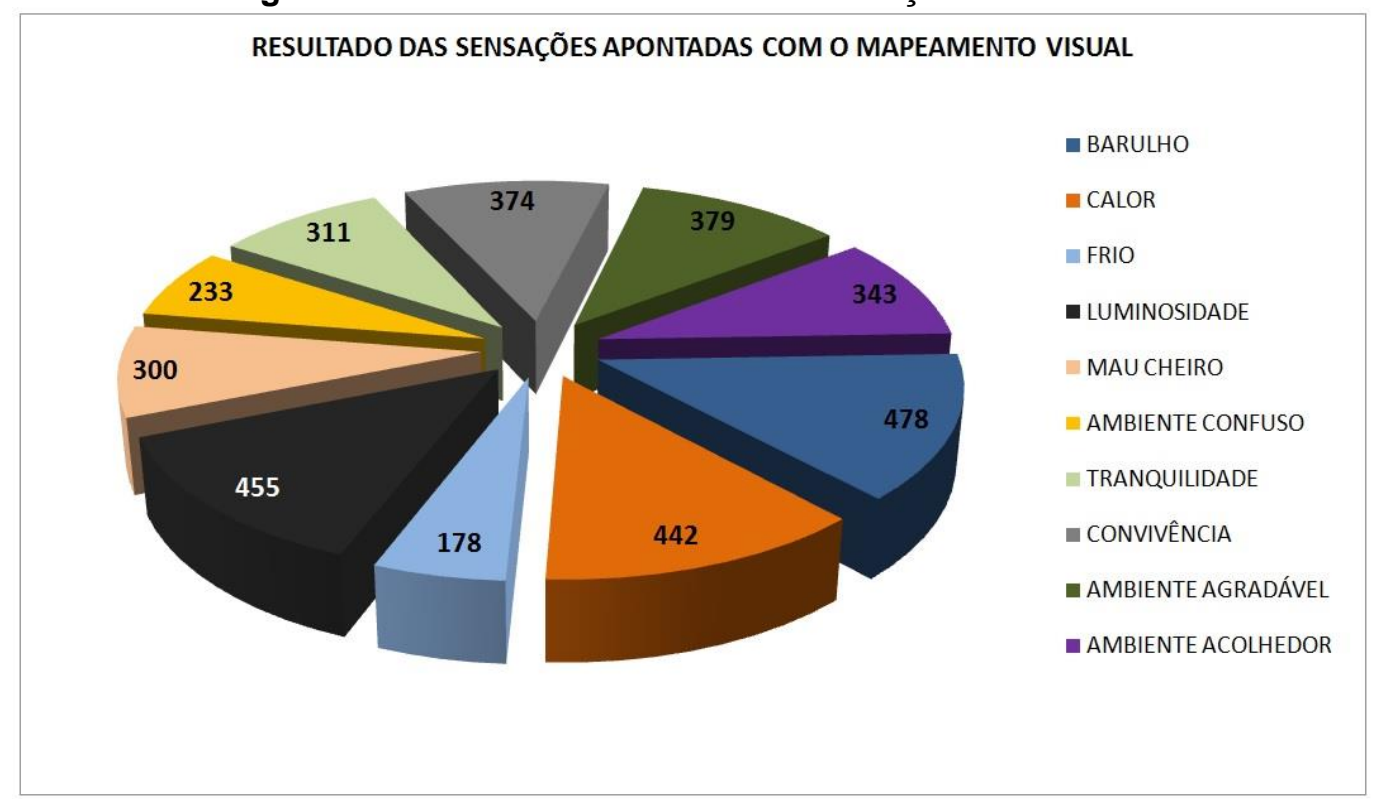

Fonte: Elaborado pelos autores.

Os resultados representam o maior número de marcações por parte dos respondentes, com destaque para os itens "barulho", "calor" e "luminosidade" que foram os mais assinalados. O barulho se deve principalmente ao fluxo externo de veículos e a movimentação de alunos na Escola José Conti localizada em frente ao complexo em estudo.

No caso do setor administrativo, o resultado aponta o item "ambiente confuso" como um dos mais assinalados, demonstrando a realidade do espaço. As canchas de bocha são um espaço de boa convivência entre seus usuários, e junto com o ginásio de esportes, possuem boa luminosidade.

O campo de society, a área das piscinas e o salão de eventos apresentam o calor como a principal sensação entre os respondentes. Os banheiros e os vestiários possuem mau cheiro, sensação que foi assinalada por grande parte das pessoas.

\subsection{Questionário}

O questionário pode ser entendido como uma ferramenta de pesquisa que contém uma série ordenada de perguntas relacionadas a um determinado assunto ou problema, que devem ser respondidas por escrito sem a presença do pesquisador. É um instrumento de grande utilidade quando se necessita descobrir regularidades entre grupos e pessoas por meio da comparação de respostas relativas a um conjunto de questões (RHEINGANTZ et al., 2009).

As perguntas foram elaboradas em linguagem de fácil compreensão e as respostas eram dissertativas sendo sua resposta avaliada individualmente (Tabela 1): 


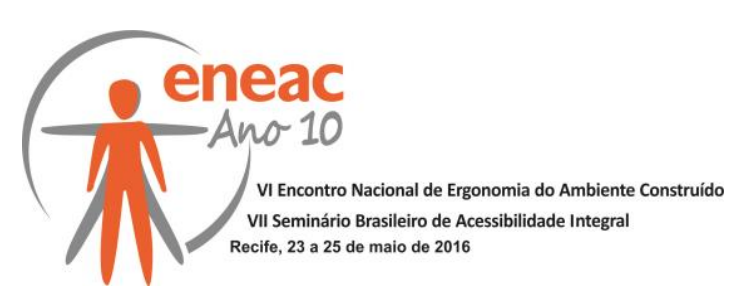

Quadro 1: Questionário e seus resultados

\begin{tabular}{|l|l|}
\hline \multicolumn{1}{|c|}{ Pergunta } & \multicolumn{1}{c|}{ Resultado } \\
\hline Se sente pertencendo a este lugar? & Resposta positiva em sua totalidade \\
\hline $\begin{array}{l}\text { Cite um ambiente representativo do complexo } \\
\text { municipal }\end{array}$ & $\begin{array}{l}\text { O salão de festas, apesar de não estar em uso, } \\
\text { foi citado por } 60 \% \text { dos respondentes, que } \\
\text { levaram em consideração os eventos que } \\
\text { aconteciam nas décadas passadas para } \\
\text { responder. }\end{array}$ \\
\hline Maior problema do complexo & $\begin{array}{l}\text { O maior problema apontado é a ausência de } \\
\text { manutenção adequada de modo geral. }\end{array}$ \\
\hline Maior potencialidade do complexo & $\begin{array}{l}\text { A sua localização no contexto urbano e os } \\
\text { espaços de circulação bem dispostos. }\end{array}$ \\
\hline Cite o que você mudaria primeiro no complexo & $\begin{array}{l}\text { Respostas variadas com predominância } \\
\text { relacionada a manutenção geral e uso das } \\
\text { piscinas }\end{array}$ \\
\hline
\end{tabular}

Fonte: Elaborado pelos autores.

\subsection{Mapa Comportamental}

O mapa comportamental é um instrumento proveniente da psicologia ambiental criado para o registro das atividades e comportamentos dos usuários de um ambiente, que permite identificar os usos, os fluxos, as interações e a distribuição dos indivíduos nele. Existem dois tipos: os mapas centrados nos lugares e os mapas centrados nos indivíduos. A aplicação de cada um deles depende do objetivo da observação.

Para esta avaliação foi aplicado o mapa comportamental centrado nos indivíduos, nos dias 06, 09 e 11 de março de 2015, com o objetivo de registrar as atividades dos usuários durante o dia. O período de observação foi de quatro horas por dia, sendo duas horas de manhã e duas horas no período vespertino.

Para efeito de aplicação do instrumento foram definidas sete áreas: o ginásio de esportes, o salão de eventos, a administração, as piscinas, o campo society, as canchas de bocha e as áreas verdes livres para circulação e o fluxo dos usuários está indicado nas Figuras 7 e 8. 


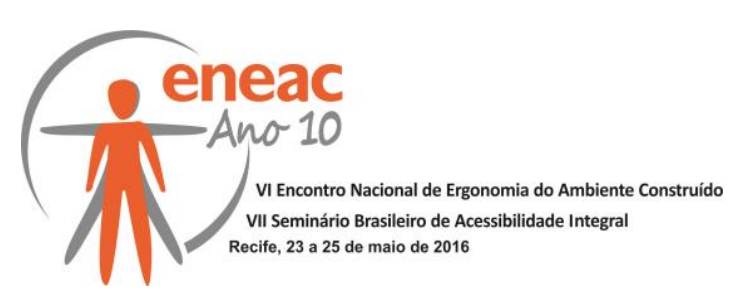

Figura 7: Divisão em setores para mapeamento comportamental.

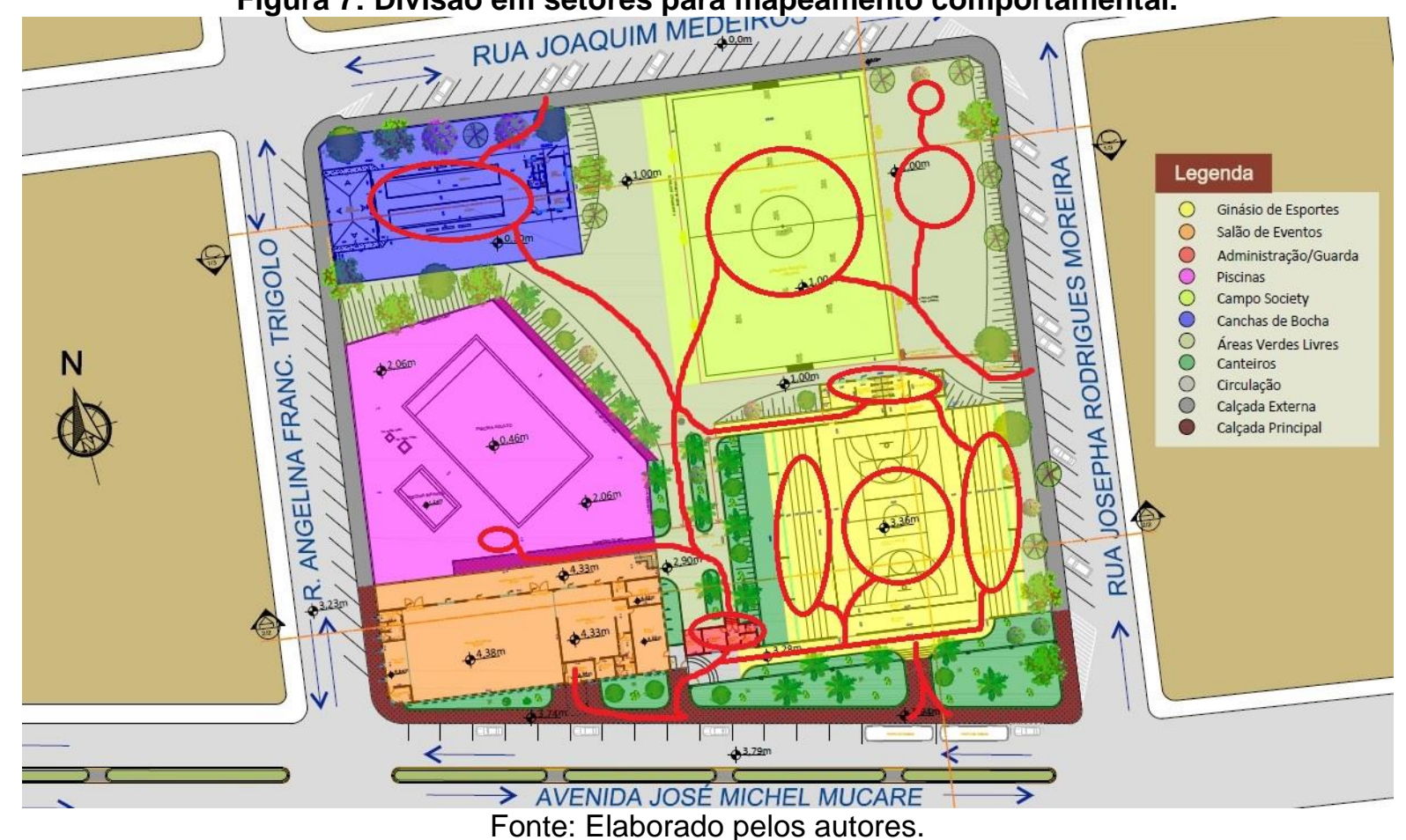

Figura 8: Mapa dos vestígios comuns identificados.

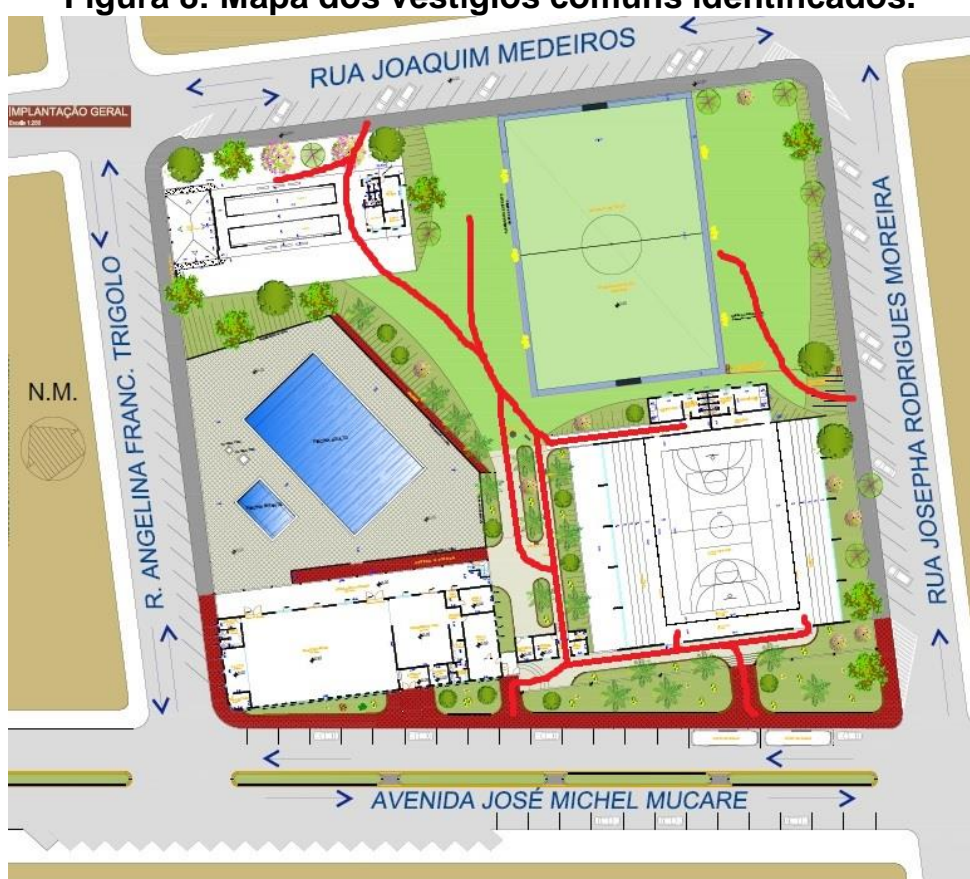

Fonte: Elaborado pelos autores.

Começando a avaliação pelo ginásio de esportes, foi possível identificar a movimentação constante dos alunos da escola José Conti no período da manhã por volta das 8 horas. No período da tarde, acontecem os treinos dos alunos da escolinha de futsal do próprio município. O ginásio fica fechado durante a noite, exceto quando estão marcadas partidas do campeonato entre os times locais ou outros eventos. 


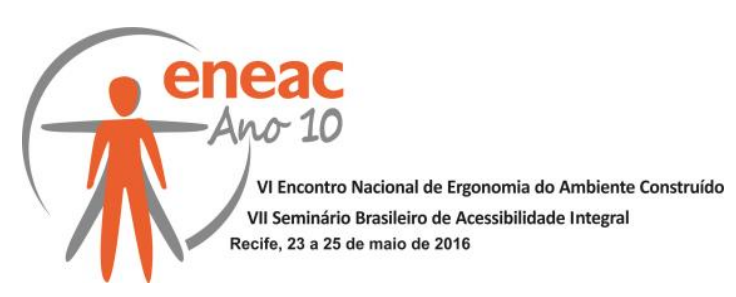

O salão de eventos fica fechado por falta de uso, por isso não foi possível identificar movimentação de pessoas nesse ambiente. A área da administração e do vigia apesar de reduzida, é utilizada para controle de entrada e a saída de pessoas.

A área das piscinas apresenta pouco, ou nenhum movimento uma vez que se encontra desativada e as piscinas vazias não atraem as pessoas para esse setor. O campo de society apresenta intensa movimentação aos finais de semana, já que é utilizada por times amadores locais. Vale destacar que o fluxo de pessoas é maior, durante as manhãs por conta da insolação amena.

As canchas de bocha são utilizadas aos domingos pelos idosos da comunidade local, e o acesso é feito pela rua Joaquim Medeiros. Um integrante de confiança do grupo de jogadores fica responsável por abrir e fechar o portão de acesso.

A circulação de pessoas nas áreas verdes é mais constante da área do vigia até o campo society e as canchas de bocha, e do acesso da Rua Josepha R. Moreira para o campo society e seus arredores. O bebedouro utilizado pelos usuários fica próximo do campo, por isso quem está no ginásio precisa sair até área externa para beber água. A arquibancada provisória ao lado do campo concentra os competidores e torcedores principalmente por estar embaixo de várias de árvores que proporcionam sombra.

De um modo geral, o instrumento foi eficaz para a análise comportamental dos usuários. Conclui-se que boa parte do complexo se encontra sem uso, que a área do vigia é muito reduzida espacialmente e que o campo de society, devido à falta de cobertura, só é utilizado no período da manhã por causa do calor excessivo na parte da tarde.

\subsection{Entrevista}

Segundo Gil (2008) pode-se definir entrevista como a técnica em que o investigador se apresenta frente ao investigado e lhe formula perguntas, com o objetivo de obtenção dos dados que interessam à investigação. A entrevista é, portanto, uma forma de interação social. Mais especificamente, é uma forma de diálogo assimétrico, em que uma das partes busca coletar dados e a outra se apresenta como fonte de informação.

Sendo assim, a entrevista foi elaborada junto ao Sr. Osvaldo Rogério Varasquim, vereador do município de Igaraçu do Tietê e ex-funcionário do complexo esportivo e do salão de eventos, visando abordar realidades aproximadas do problema pesquisado.

O espaço em estudo já foi palco de grandes eventos municipais e regionais. Sediou diversas competições esportivas, como campeonatos de futsal, de basquete, de vôlei, de bocha, de natação, entre outros. O ginásio de esportes já foi utilizado para confraternizações municipais, como entrega de diplomas para alunos de pré-escolas, ensaios de coreografias para eventos municipais, entre outros.

Segundo o entrevistado, os jogadores que participavam dos campeonatos amadores locais, contribuíam com um valor simbólico em dinheiro, como se fosse o valor da entrada, e os organizadores compravam lanches e refrigerantes, que eram servidos depois do término das partidas.

Já o salão de eventos, foi muito utilizado pela comunidade para festas locais, como: casamentos comunitários, bailes, jantares, entre outros. Era muito frequentado por idosos na época, e passou a ser conhecido como clube da terceira idade.

\subsection{Análise dos dados}

De acordo com a análise dos dados obtidos, pôde-se observar que os resultados foram bastante similares nos diferentes instrumentos aplicados. 


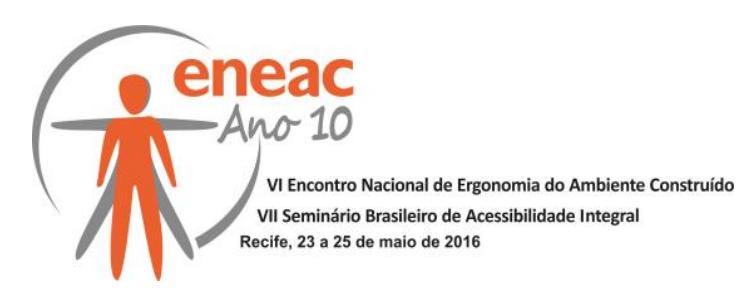

De modo geral, percebe-se que a avaliação dos espaços na etapa de mapa comportamental condiz com as respostas dadas para o questionário e a análise walkthrough.

A localização, a ventilação natural e o entorno do complexo foram avaliados pelos participantes como as principais potencialidades, e a falta de manutenção adequada junto a ausência de conservação dos objetos e da desativação da piscina, foram os maiores fatores negativos apontados.

A entrevista com o Sr. Osvaldo Rogério Varasquim relatou fatos marcantes da história do espaço em estudo. Por meio da aplicação do mapeamento visual, foi possível identificar que todos os banheiros possuem mau cheiro e que o barulho foi o item mais assinalado pelos participantes.

\section{RECOMENDAÇÕES}

Após a análise dos resultados e cruzamento dos dados obtidos, foram identificadas algumas recomendações para uma possível futura intervenção no espaço. Essas recomendações foram divididas em: curto, médio e longo prazo, apresentadas a seguir.

Quadro 2: Recomendações de curto, médio e longo prazo para o Complexo Esportivo

\begin{tabular}{|c|c|}
\hline Prazo & Recomendações \\
\hline Curto & $\begin{array}{l}\text { - Limpeza em geral; } \\
\text { - } \text { pinturas de paredes e demarcações de quadras e campos de } \\
\text { - } \text { mampetições esportivas; } \\
\text { - manutenção de portas e janelas danificadas; } \\
\text { - recuperar jardinagem e paisagismo; } \\
\text { - manutenção do campo e alambrados; } \\
\text { - manutenção de alguns equipamentos visíveis de elétrica e hidráulica } \\
\text { (tomadas, válvulas de pias, torneiras, etc.), iluminação (troca de } \\
\text { lâmpadas, refletores mais potentes, etc.) visando otimizar o uso de } \\
\text { energia. }\end{array}$ \\
\hline Médio & $\begin{array}{l}\text { - } \quad \text { Troca de portas de madeiras e janelas de aço; } \\
\text { - } \quad \text { impermeabilização de telhados e paredes; } \\
\text { - } \quad \text { reforma dos banheiros (troca de revestimentos, vasos sanitários, } \\
\text { - } \quad \text { clias, etc.); } \\
\text { - } \quad \text { instalaçação de sistemas de monitoramento e segurança; } \\
\text { - implantação de sinalizações internas como pisos táteis em escadas } \\
\quad \text { e rampas, e informações das distribuições espaciais na parede. }\end{array}$ \\
\hline Longo & 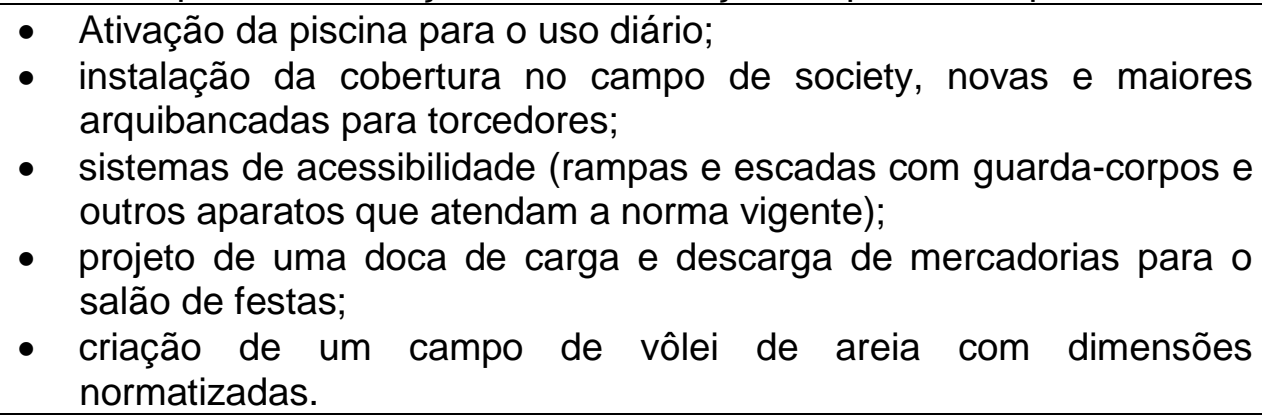 \\
\hline
\end{tabular}


